\title{
EFEITO DA HIDROCORTISONA SOBRE A RESISTENNCIA CICATRICIAL DA PELE EM CAMUNDONGOS
}

\author{
EFFECT OF HYDROCORTISONE ON TENSIL SKIN CICATRIZATION IN MOUSE
}

\author{
Leonardo de Souza Vasconcellos ${ }^{1}$ \\ Luiz Ronaldo Alberti ${ }^{2}$ \\ Cristiana Buzelin Nunes ${ }^{3}$ \\ Andy Petroianu-TCBC-MG ${ }^{4}$
}

\begin{abstract}
RESUMO: Objetivo: O efeito da corticoterapia sobre a cicatrização de feridas cirúrgicas vem apresentando resultados conflitantes na literatura, principalmente quando usada por tempo prolongado. O objetivo do presente trabalho foi comparar a resistência cicatricial da pele de camundongos submetidos à administração de hidrocortisona, em distintos períodos pós-operatórios. Método: Foram estudados 150 camundongos machos submetidos à incisão e sutura da pele dorsal, divididos em cinco grupos. No Grupo $1(n=6)$ avaliou-se apenas a resistência da pele íntegra. Nos demais grupos $(n=36)$ realizaram-se incisão e sutura na pele, sendo que o Grupo 2 (controle) submeteu-se apenas à operação, enquanto o Grupo 3 recebeu, ainda, solução salina a 0,9\% e os Grupos 4 e 5 receberam $10 \mathrm{mg} / \mathrm{kg} / \mathrm{dia}$ de hidrocortisona local e sistêmica, respectivamente. Avaliaram-se a resistência cicatricial e a variação ponderal nos sétimo e 21ํ dias pós-operatórios. Resultados: Os camundongos que receberam corticóide, Gupos 4 e 5, apresentaram decréscimo ponderal significativo ( $<<0,02)$. Quanto à resistência cicatricial da pele, os Gupos 3, 4 e 5 apresentaram valor inferior ao Grupo 2 no sétimo dia pós-operatório $(\mathrm{p}<0,02)$. No $21^{\circ}$ dia, a queda foi observada apenas no grupo submetido à solução salina ( $\left.p<0,05\right)$. Conclusão: Os resultados indicam uma diminuição da resistência cicatricial apenas nos camundongos tratados com corticóide em intervalos menores de tratamento.
\end{abstract}

Descritores: Corticosteróides; Cicatrização de feridas; Via de administração dos corticóides; Hidrocortisona.

\section{INTRODUÇÃO}

O efeito da corticoterapia, sobre a cicatrização de feridas cirúrgicas apresenta resultados conflitantes na literatura, principalmente em tempo prolongado ${ }^{1,2,3,4,5}$. Vários são os fatores para essa controvérsia, dependendo do tipo e da dose dos corticosteróides empregados, das várias espécies de animais estudadas, da duração do tratamento e dos métodos de avaliação da eficácia da cicatrização.

A maioria dos trabalhos mostra efeitos adversos da corticoterapia sobre as cicatrizações de feridas. Diethelm ${ }^{6}$, em estudo sobre complicações da corticoterapia, concluiu que sua administração pré ou trans-operatória, está associada a maior incidência de infecção e retardo da cicatrização. Alrich et al. ${ }^{1}$ verificaram que ratos tratados com ACTH e cortisona também tiveram a cicatrização prejudicada, principalmente com doses maiores e intervalos menores de tratamento. Vogel ${ }^{5}$ observou que ratos tratados com altas doses de cortisol e prednisolona tinham uma diminuição da tensão cicatricial da pele. Por outro lado, segundo esse autor, corticoterapia em baixas doses e tempo prolongado acompanha-se de aumento da resistência cicatricial.

1. Acadêmico de Medicina da Faculdade Ciências Médicas de Minas Gerais, Bolsista de Iniciação Científica da FAPEMIG.

2. Acadêmico de Medicina da Faculdade Ciências Médicas de Minas Gerais, Bolsista de Iniciação Científica do CNPq.

3. Anatomopatologista do Instituto Moacyr Junqueira e da Santa Casa de Belo Horizonte.

4. Professor Titular do Departamento de Cirurgia da Faculdade de Medicina - UFMG, Livre-Docente da Faculdade de Medicina de Ribeirão Preto - USP, Livre-Docente da Escola Paulista de Medicina - UNIFESP, Doutor em Fisiologia e Farmacologia, Pesquisador IA do CNPq.

Recebido em 01/06/2000

Aceito para publicação em 15/03/2001

Trabalho realizado no Departamento de Cirurgia, Faculdade de Medicina da UFMG, com auxílio do CNPq e da FAPEMIG. 
Stern e Shuman ${ }^{7}$ encontraram efeitos conflitantes com doses moderadas e baixas de corticosteróides. Já Harvey et al. ${ }^{8}$ verificaram até um aumento da síntese de colágeno em culturas de fibroblastos de pele embrionária humana, acrescentando-se baixas concentrações de corticóides.

Frente à necessidade de mais estudos comparativos dos efeitos dos corticóides sobre a cicatrização da pele, o presente trabalho, pertencente a uma linha de pesquisa sobre cicatrização 9,10,11, teve como objetivo comparar a cicatrização de lesão cirúrgica sobre a pele de camundongos submetidos à administração de hidrocortisona, em distintos períodos pós-operatórios.

\section{MÉTODO}

O presente trabalho foi realizado de acordo com as recomendações das Declarações de Helsinque e as Normas Internacionais de Proteção aos Animais, e aprovado por Comitê de Ética da Universidade Federal de Minas Gerais ${ }^{12,13}$.

Foram utilizados 150 camundongos machos e albinos, da raça Swiss, linhagem CF-1 e pesando entre 35 e 45 gramas. Os animais foram divididos aleatoriamente em cinco grupos:

- Grupo $1(n=6)$ : controle, não operado. Avaliação da tensão da pele íntegra;

- Grupo $2(\mathrm{n}=36)$ : submetido à cirurgia e avaliação da resistência da cicatrização nos sétimo e $21^{\circ}$ dias pósoperatórios;

- Grupo 3 ( $\mathrm{n}=36)$ : injeção diária de solução salina a $0,9 \%$, via subcutânea no local da cirurgia, a partir de dois dias antes da operação e continuada até a avaliação da resistência da cicatrização nos sétimo e $21^{\circ}$ dias pós-operatórios;

- Grupo $4(\mathrm{n}=36)$ : injeção diária de hidrocortisona, na dose de $10 \mathrm{mg} / \mathrm{kg} / \mathrm{dia}$, via subcutânea, no local da cirurgia, iniciada dois dias antes da operação e continuada até a avaliação da resistência da cicatrização nos sétimo e $21^{\text {o }}$ dias pós-operatórios;

- Grupo $5(\mathrm{n}=36)$ : injeção diária de hidrocortisona, na dose de $10 \mathrm{mg} / \mathrm{kg} / \mathrm{dia}$, via intraperitoneal, iniciada dois dias antes da cirurgia e continuada até a avaliação da resistência da cicatrização nos sétimo e $21^{\circ}$ dias pósoperatórios.

Os animais foram acompanhados diariamente e receberam dieta à base de água e ração para ratos, à vontade.

A operação, conduzida sob anestesia inalatória com éter, foi a mesma em todos animais. Realizou-se tricotomia e incisão na região dorsal mediana craniocaudal da pele, medindo $3,0 \mathrm{~cm}$ de comprimento, poupando os músculos adjacentes. Em seguida, as bordas foram suturadas, com quatro pontos simples, utilizando-se fio sintético polipropileno monofilamentar 4-0.

A morte dos animais foi induzida com dose letal inalatória de éter. A influência da hidrocortisona na resistência da cicatriz foi estudada por meio dos seguintes parâmetros:
- variação ponderal ocorrida durante o período de acompanhamento dos animais;

- presença de complicações pós-operatórias gerais e da pele;

- medidas das tensões de ruptura da pele íntegra e da cicatriz;

- avaliação histológica do tecido cicatricial.

Os camundongos foram pesados imediatamente após a sua morte. Em cada animal dos Grupos 4 e 5, foi injetado diariamente $0,1 \mathrm{ml}$ de solução contendo hidrocortisona na dose de $10 \mathrm{mg} / \mathrm{kg} / \mathrm{dia}$, no local da cicatriz (Grupo 4) ou intraperitoneal (Grupo 5). No grupo que recebeu apenas solução salina, o volume injetado foi também de $0,1 \mathrm{ml}$. Essas injeções tiveram o objetivo de comparar os efeitos sistêmico e local do corticóide, bem como a distensão tissular no local da incisão sobre o processo cicatricial.

A resistência da cicatrização da pele foi aferida retirando-se um fragmento transversal à cicatriz, medindo 4,0 X $1,0 \mathrm{~cm}$ e tendo a cicatriz em sua parte média. Os pontos foram cuidadosamente retirados e $\mathrm{o}$ fragmento foi pinçado em suas extremidades por duas pinças de Duval de $22 \mathrm{~cm}$ e pesando $58 \mathrm{~g}$ cada. Uma pinça foi presa a um suporte metálico, enquanto a outra foi amarrada à alça de um frasco de Becker de plástico com capacidade para 1.000ml (Figura 1). Um filete de água destilada a uma velocidade constante de $650 \mathrm{ml} / \mathrm{min}$ foi enchendo o frasco, até a ruptura do segmento. Mediu-se o volume do líquido, transformado em gramas, que foi somado ao peso do frasco e ao da pinça amarrada a ele $(120 \mathrm{~g})$.

Os estudos histológicos foram conduzidos em preparações coradas por hematoxilina-eosina e tricrômico de Gomori; mediu-se a espessura da neoformação fibrosa cicatricial, em três regiões diferentes (próximo à extremidade cranial, na parte média e próximo à borda caudal).

Os resultados foram comparados por meio de testes $t$ de Student e qui-quadrado. As diferenças foram consideradas significativas para valores maiores aos correspondentes a $\mathrm{p}<0,05$.

\section{RESULTADOS}

Todos os camundongos sobreviveram ao experimento e evoluíram satisfatoriamente. As cicatrizações cutâneas ocorreram em todos os animais, porém em progressões diferentes.

A variação ponderal média de todos os grupos estudados encontra-se na Tabela 1 . Os camundongos que receberam hidrocortisona, Grupos 4 e 5, apresentaram decréscimo ponderal significativo $(p<0,02)$, tanto no sétimo dia, quanto no 21 dia pós-operatório, ao serem comparados com os animais que sofreram apenas cirurgia, Grupo 2. Em relação aos que receberam solução salina, Grupo 3, a diferença ponderal só foi significativa no sétimo dia pósoperatório.

Os resultados da tensão cicatricial média encontramse resumidos na Tabela 2. Os camundongos dos Grupos 3 , 4 e 5 apresentaram valores inferiores ao Grupo 2 apenas no sétimo dia pós-operatório $(\mathrm{p}<0,02)$. A longo pra- 


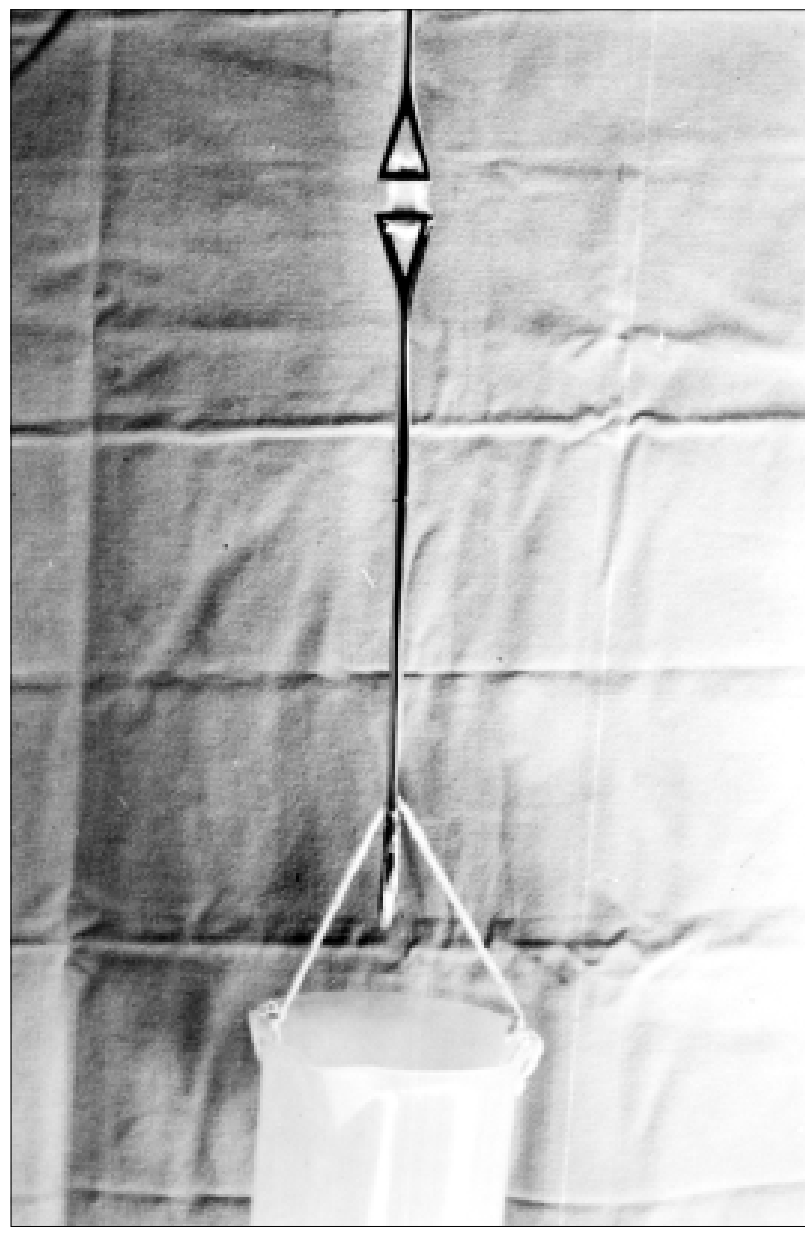

Figura 1 - Sistema utilizado para mensuração cicatricial mostrando retalho cutâneo com cicatriz em sua parte média acoplado às pinças de Duval. zo, no $21^{\text {o }}$ dia pós-operatório, apenas o Grupo 3 mostrou diferença estatisticamente significativa em relação ao Grupo 5 ( $\mathrm{p}<0,05)$.

Em todos os camundongos operados (Grupos 2, 3, 4 e 5), a redução nos valores da tensão necessária para romper as cicatrizações nos sétimo e $21^{\circ}$ dias pós-operatórios foi significativa em relação aos animais que não sofreram operação, Grupo 1, mostrando p < 0,001.

$\mathrm{Na}$ avaliação macroscópica da cicatrização no sétimo dia pós-operatório, observou-se, nos Grupos 4 e 5, área cicatricial mais frouxa. Já nos demais grupos, a cicatrização mostrou-se mais firme. No 21ํ dia pós-operatório todos os grupos tiveram cicatrizações firmes. Não se evidenciaram áreas de infecção nas cicatrizes.

$\mathrm{Na}$ avaliação histológica, com coloração de rotina (hematoxilina e eosina - H.E.) e coloração especial para tecido conjuntivo (tricrômico de Gomori), verificou-se, no sétimo dia pós-operatório, que as cicatrizações apresentaram aumento discreto do colágeno, infiltrado inflamatório de polimorfonucleares, plasmócitos, linfócitos e macrófagos, e congestão vascular, também reduzidos. Nos Grupos 4 e 5, notou-se padrão morfológico mais heterogêneo, com reação inflamatória mais presente e menor número de fibroblastos e feixes de colágeno (Figura 2A). Já no 21ํ dia pós-operatório, constatou-se padrão morfológico mais homogêneo, com melhor arranjo de fibroblastos e fibras colágenas, que se encontravam mais espessas e com distribuição mais ordenada e paralelas entre si, não havendo diferença entre os grupos (Figura 2B). Apenas no Grupo 3 houve reação inflamatória discreta. Na quantificação histométrica da espessura do tecido cicatricial, não foram assinaladas diferenças significativas.

Tabela 1

Peso (g) de camundongos nos sétimo e 21ํ dias pós-operatórios

\begin{tabular}{|c|c|c|c|c|}
\hline \multirow[b]{3}{*}{ Grupos } & \multicolumn{2}{|c|}{ 7oo dia } & \multicolumn{2}{|c|}{$21^{o}$ dia } \\
\hline & \multicolumn{2}{|c|}{ Peso } & \multicolumn{2}{|c|}{ Peso } \\
\hline & Inicial & Final & Inicial & Final \\
\hline $2(\mathrm{n}=36)$ & $42,5 \pm 2,1$ & $43,2 \pm 2,5$ & $42,7 \pm 2,3$ & $43,3 \pm 3,7$ \\
\hline $3(\mathrm{n}=36)$ & $41,9 \pm 2,4$ & $41,5 \pm 2,9$ & $42,4 \pm 2,7$ & $40,5 \pm 5,5$ \\
\hline $4(n=36)$ & $42,6 \pm 2,6$ & $35,4 \pm 2,4 *$ & $42,5 \pm 2,2$ & $39,5 \pm 3,6 *$ \\
\hline $5(\mathrm{n}=36)$ & $42,5 \pm 2,5$ & $37,5 \pm 3,3 *$ & $42,8 \pm 2,1$ & $38,3 \pm 4,0 *$ \\
\hline
\end{tabular}

Notas: * Comparação dos resultados em relação ao Grupo $2(p<0,02)$

Peso do Grupo 1: 41,4 +/- 2,5

Grupo 1: controle, não operado

Grupo2: apenas cirurgia

Grupo 3: cirurgia + solução salina a 0,9\%

Grupo 4: cirurgia + hidrocortisona local

Grupo 5: cirurgia + hidrocortisona sistemica 
Tabela 2

Tensão cicatricial (g) da pele de camundongos nos sétimo e $21^{\circ}$ dias pós-operatórios

\begin{tabular}{l|c|c|c}
\hline \multirow{2}{*}{ Grupos } & Não operados & 70 dia & $21^{\circ}$ dia \\
\cline { 2 - 4 } $1(\mathrm{n}=6)$ & Tensão & Tensão & Tensão \\
$2(\mathrm{n}=36)$ & $1147,5 \pm 3,2$ & - & $757,5 \pm 2,1$ \\
$3(\mathrm{n}=36)$ & - & $240,0 \pm 8,5$ & $645,0 \pm 6,2 * *$ \\
$4(\mathrm{n}=36)$ & - & $142,5 \pm 5,4^{*}$ & $750,0 \pm 2,2$ \\
$5(\mathrm{n}=36)$ & - & $147,5 \pm 7,3^{*}$ & $780,0 \pm 2,5$ \\
\hline
\end{tabular}

Notas: * Comparação dos resultados em relação ao Grupo $2(p<0,02)$

** Comparação do resultado em relação ao Grupo 5 ( $p<0,05)$

Grupo 1: controle, não operado

Grupo2: apenas cirurgia

Grupo 3: cirurgia + solução salina a 0,9\%

Grupo 4: cirurgia + hidrocortisona local

Grupo 5: cirurgia + hidrocortisona sistêmica

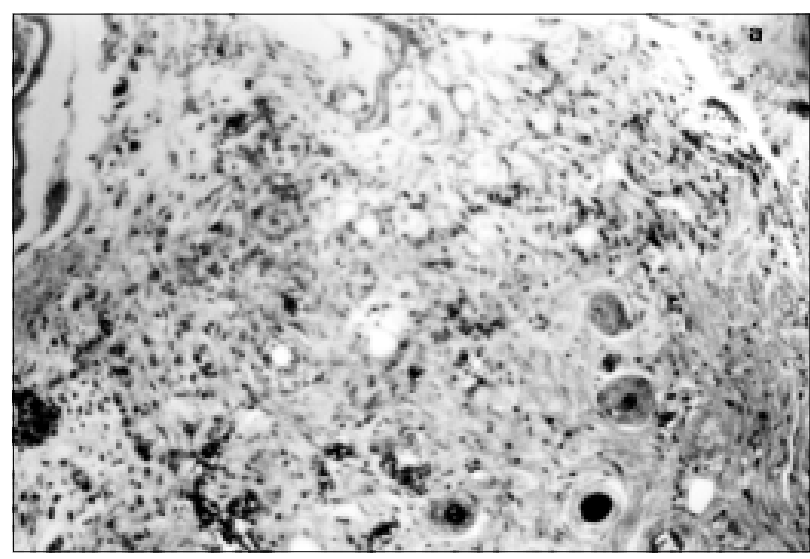

Figura 2A - Corte histológico de pele do camundongo no 12 do Grupo 4 no sétimo dia pós-operatório. Observa-se padrão morfológico heterogêneo, com infiltrado inflamatório marcante, hiperemia vascular, menor número de fibroblastos e feixes de colágeno desordenados e frouxos. Coloração tricrômico de Gomori, $40 X$

\section{DISCUSSÃO}

Fatores que afetam a cicatrização são pesquisados continuamente, sendo o seu retardo um dos efeitos bastante discutido e controverso dos corticóides. Embora existam diversos estudos experimentais sobre a relação entre os fenômenos cicatriciais e o uso de corticosteróides, a multiplicidade metodológica dificulta sua avaliação $1,2,3,4,5,11$.

A dose de hidrocortisona escolhida, no presente trabalho, teve como base estudos anteriores que verificaram ser $10 \mathrm{mg} / \mathrm{kg} / \mathrm{dia}$ a concentração mínima necessária para afetar a cicatrização de feridas, sendo, também, proporcional às prescritas em diversos tratamentos clínicos $5,11,14,15,16$. Seguindo orientações da literatura ${ }^{6,17}$, a administração do fármaco foi iniciada no pré-operatório (por dois dias), es-

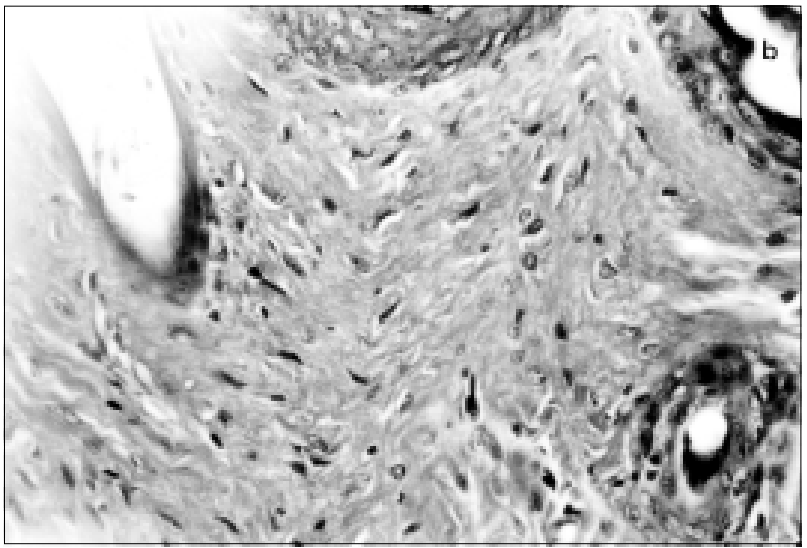

Figura 2B - Corte histológico de pele do camundongo no 5 do Grupo 4 no $21^{\circ}$ dia pós-operatório. Observa-se padrão morfológico homogêneo, com melhor arranjo de fibroblastos e feixes de colágeno, encontrando-se mais espessados, ordenados e paralelos entre si. Coloração tricrômico de Gomori, 20X.

tendendo-se até o dia em que os animais foram mortos. Segundo vários autores ${ }^{6,18}$, quando a droga é administrada previamente ao ato cirúrgico e mantida no pós-operatório, os efeitos prejudiciais dos corticóides são mais evidentes.

A redução ponderal dos camundongos submetidos aos corticóides também já é conhecida na literatura. De acordo com vários autores $3,4,9,10,11,17$, a corticoterapia utilizada em animais participa de um processo metabólico complexo e que resulta em desnutrição. Ainda não se conseguiu uma explicação satisfatória para esse fenômeno, contudo essa queda do estado geral dos animais poderia contribuir para o retardo cicatricial.

Em estudo prévio, mostrou-se que a perda de peso interfere com a cicatrização de anastomoses colônicas em ratos, apenas após sete semanas de restrição alimentar ${ }^{18}$. 
Já no presente trabalho, o período de acompanhamento dos camundongos esteve muito aquém do descrito na literatura e mesmo assim houve redução ponderal.

Os dados deste trabalho indicam uma queda na tensão cicatricial da pele em camundongos em uso de hidrocortisona, no sétimo dia pós-operatório. Tal resultado pode ser devido ao retardo na deposição de colágeno, com conseqüente redução da resistência cicatricial. No acompanhamento de sete dias, todos os grupos apresentaram resistência cicatricial inferior à encontrada após 21 dias. No início, o tecido cicatricial ainda é muito tênue e sua resistência é pequena, o que dificulta avaliar o efeito do corticóide. Mesmo assim, observou-se que os grupos tratados com hidrocortisona tiveram resistência cicatricial menor do que a do grupo controle ( $\mathrm{p}<0,02$ ). Já no 21 ㅇ dia pós-operatório, o processo cicatricial de todos os grupos estava organizado, não havendo diferença relacionada ao fármaco ( $p>0,05)$. Entretanto, observou-se uma menor resistência com o uso de solução salina local em relação ao grupo tratado com corticóide sistêmico ( $\mathrm{p}<0,05)$.

A histologia revelou atraso na cicatrização em camundongos que receberam hidrocortisona no sétimo dia pós-operatório. Nesse período, o grupo controle já evoluía para a fase de fibroplasia, com intenso povoamento de fibroblastos e deposição de fibras colágenas. Os grupos que receberam corticóide ainda estavam no estádio inflamatório, com escassas células fibroblásticas e fibras colágenas tênues e desordenadas. Esse fato não foi verificado no $21^{\circ}$ dia pós-operatório, quando todos os grupos encontravam-se em estádio semelhante de cicatrização e maturação, com tecido conectivo bem formado e rico em fibras colágenas ordenadas.

Embora neste trabalho tenha sido observada diminuição da tensão cicatricial cutânea induzida a curto prazo por corticóide, esses dados não permitem explicar sua fisiopatologia. Sabe-se que o processo cicatricial normal apresenta sequiência já conhecida ${ }^{19}$. A resposta inflamatória imediata ao trauma caracteriza-se pela presença de hemorragia, edema, congestão vascular e infiltrado inflamatório, durando em média cinco dias. Posteriormente, a fase de fibroplasia acompanha-se de neoformação vascular e proliferação de fibroblastos, estendendo-se em média até o 14ㅇ․ Finalmente, o ciclo da maturação modela o colágeno e desvasculariza o tecido de granulação, podendo durar até dois anos.

A ação do corticóide pode interferir em qualquer um desses processos. Segundo alguns autores, esse fármaco promove a estabilização da membrana lisossômica, dificultando sua lise com conseqüente redução da reação inflamatória inicial, comprometendo o restante do processo ${ }^{16}$. Outra teoria sugere ação inibitória da proliferação de fibroblastos, reduzindo a síntese de colágeno. Existe ainda a possibilidade da antagonização dos efeitos angiogênicos e inibição da colagenase ${ }^{20}$. Todas essas explicações poderiam justificar a redução da tensão cicatricial, porém ainda são necessários maiores estudos para esclarecer essa questão.

A transposição dos achados experimentais para a prática clínica deve ser feita com cautela. Segundo Pri$\mathrm{ce}^{21}$, analisando retrospectivamente pacientes portadores de retocolite ulcerativa em uso de corticoterapia, não houve alteração nas complicações das anastomoses ileorretais. Green ${ }^{14}$, também em estudo retrospectivo, observou efeitos adversos nas lesões cirúrgicas em pacientes em uso de corticóides.

Concluindo, de acordo com os resultados do presente trabalho, a hidrocortisona reduz a resistência cicatricial da pele na primeira semana pós-operatória, em camundongos.

\begin{abstract}
Background: The effect of a corticotherapy on skin wound healing is conflitant in the literature. The objective of the our research was to compare the resistance of mice skin wound healing submitted to hydrocortisone administration, in different postoperative periods. Method: A skin incision and sutures were performed on 150 male mice. The animals were divided into five groups. The Group $1(n=6)$ was assessed on resistance of the integre skin. The other groups $(n=36)$ were submitted to incision on their dorsal skin. The Group 2 was submitted only to operation. The Group 3 received 0.9\% saline solution. The groups 4 and 5 received $10 \mathrm{mg} / \mathrm{kg} /$ day local or sistemic hydrocortisone. The resistance of the wound healing and the weight variation were studied on the $7^{\text {th }}$ and $21^{\text {st }}$ postoperative days. Results: The mice that received corticoid, groups 4 and 5, presented significant decreases on their weight $(P<0,02)$. Groups 3, 4 and 5 showed lower resistance than Group 2 on the $7^{\text {th }}$ postoperative day $(p<0,02)$. On the $21^{\text {st }}$ day, only the animals of the Group $3(P<0,05)$ had lower resistance than the other groups. Conclusion: These results indicate a decreased of the wound healing resistance in the presence of corticosteroid only after a short time treatment.
\end{abstract}

Key Words: Corticosteroids; Wound healing; Corticosteroid administration; Hydrocortisone.

\title{
REFERÊNCIAS
}

1. Alrich EM, Carter JP, Lehman EP. The effect of ACTH and cortisone on wound healing. Ann Surg 1951, 133: 783789.
2. Howes EL, Plotz CM, Blunt JW et al. Retardation of wound healing by cortisone. Surgery 1950,28 : 177180 . 
3. Oxlund H, Fogdestam I, Viidik A. The influence of cortisol on wound healing of the skin and connective tissue response. Surg Gynecol Obstet 1979, 148: 876-879.

4. Sandberg N. Time relationship between administration of cortisone and wound healing in rats. Acta Chir Scand 1964, 127: 446-455.

5. Vogel HG. Tensile strength of skin wounds in rats after treatment with corticosteroids. Acta Endocrinol 1970, 64: 295-303.

6. Diethelm AG. Surgical management of complications of steroid therapy. Ann Surg 1977, 183: 251-260.

7. Stern SF, Shuman A. The effect of locally administered corticosteroids on the healing times of surgical induced wounds in guinea pigs. J Am Podiatry Med Assoc 1973, 63: 374-382.

8. Havery WG, Grahame R, Panayi GS. Effects of steroid hormones on human fibroblasts in vitro. Ann Rheum Dis 1974, 33: 437-441.

9. Melo MAB, Almeida LM, Petroianu A et al. Cicatrização de anastomose colônica em ratos submetidos a diferentes preparos colônicos. Rev Bras Colo-Proct 1996, 16: $19-22$.

10. Arantes VA, Okawa RY, Petroianu A et al. Influência da icterícia obstrutiva na cicatrização de pele e de anastomose jejunal em ratos. Rev Col Bras Cir 1999, 26: 269-273.

11. Arantes VN, Okawa RY, Petroianu A et al. Efeito da metilprednisolona sobre a tensão anastomótica jejunal. Arq Gastroenterol 1994, 31: 97-101.

12. Cooper JE. Ethics and Laboratory animals. Vet Rec 1985, 116: 594-595.

13. Petroianu A. Pesquisa experimental. In Petroianu A (ed) Ética, Moral e Deontologia Médicas. Rio de Janeiro. Ganabara Koogan, SA 200, pp. 185-190.

14. Green JP. Steroid therapy and wound healing in surgical patients. Br J Surg 1965, 52: 523-525.

15. Martins Jr A, Guimarães AS, Ferreira AL. Efeito dos corticosteróides na cicatrização de anastomoses intestinais. Acta Cir Bras 1992, 7: 28-30.
16. Gottrup F, Oxlund H. Healing of incisional wounds in stomach and duodenum. J Surg Res 1981, 31: 165-170.

17. Aszodi A, Ponski JL. Effects of corticosteroid on healing bowel anastomosis. Am Surg 1984, 50: 546-548.

18. Irvin TT. Effects of malnutrition and hyperalimentation on wound healing. Surg Gynecol Obstet 1978, 146: 3337.

19. Irvin TT, Devon. Simple skin closure. Br J Hosp Med 1985, 33: 325-330.

20. Kim CS, Buchmiller TL, Fonkalsrud EW et al. The effect of anabolic steroids on ameliorating the adverse effects of chronic corticosteroids on intestinal anastomotic healing in rabbits. Surg Gynecol Obstet 1993, 176: 73-79.

21. Price LA. The effect of systemic steroids on ileorectal anastomosis in ulcerative colitis. Br J Surg 1968, 55: 839840 .

Endereço para correspondência:

Prof. Andy Petroianu

Av. Afonso Pena, 1.626/1.901

30130-005, Belo Horizonte-MG 